\title{
Bedeutung, Ausprägungen und Grenzen der direkten Demokratie im Völkerrecht
}

\author{
Alexander Proelß/Zlatko Bajić
}

\section{Einführung}

Es besteht heutzutage Einigkeit über zwei mögliche Verständnisvarianten des Konzepts der direkten Demokratie. ${ }^{1}$ Direkte - oder plebiszitäre - Demokratie kann zunächst auf die allgemeine Ausgestaltung des innerstaatlichen Herrschaftssystems, d.h. auf die Staatsform hinweisen. Letztere ist dann dadurch gekennzeichnet, dass ein Großteil der politischen Entscheidungen im Staat unmittelbar vom Volk selbst getroffen wird. Das Regierungssystem eines solchen Staates sieht also vor, dass das Staatsvolk die Staatsgewalt nicht nur hervorbringt, sondern diese vielmehr selbst ausübt und damit unmittelbarer Träger der Staatsgewalt ist (direkte Demokratie als Herrschafts- bzw. Staatsform). ${ }^{2}$ Alternativ kann sich der Begriff der direkten Demokratie auch auf einzelne Entscheidungsverfahren beziehen, mit denen sich das Volk in Form von Volksversammlungen, -initiativen, -abstimmungen, -befragungen oder Referenden ${ }^{3}$ unmittelbar an konkreten Sachfragen beteiligt. In dieser Ausprägung wirkt das Volk innerhalb eines ansonsten repräsentativ ausgestalteten Systems ergänzend bzw. korrigierend auf das politische Entscheidungssystem ein (direkte Demokratie als Entscheidungsverfahren). ${ }^{4}$

1 Vgl. Karl Hernekamp, Formen und Verfahren der direkten Demokratie, 1979, S. 10 f.

2 Vgl. Roman Herzog, Allgemeine Staatslehre, 1971, S. 204 f. Als berühmtester Vertreter eines solchen direkt-demokratischen Staatsmodells gilt Jean-Jacques Rousseau (Du contract social [1762], Nachdruck 2010, Livre II chap. 6 und Livre III chap. 1). Ihm zufolge sollten die Gesetze unmittelbar vom Volk beschlossen werden, so dass im Ergebnis eine Identität zwischen dem Gesetzgebenden und dem Gesetzadressaten bestehe. Vgl. insoweit auch die von Carl Schmitt geprägte Formel von der „Identität von Herrscher und Beherrschten, Regierenden und Regierten, Befehlenden und Gehorchenden“ (ders., Verfassungslehre [1928], 8. Aufl. 1993, S. 234).

3 Eine Kategorisierung der einzelnen Typen oder Verfahren der direkten Demokratie, insbesondere danach, ob das Volk selbst eine Vorlage einbringt (sog. Volksinitiative) oder ob es über eine vorgelegte Vorlage abstimmt (Volksabstimmung, -befragung, Referendum), ist für die vorliegende Untersuchung nicht erforderlich. Insoweit sei auf die Darstellung bei Hernekamp, Formen (Fn. 1), S. 20 ff. verwiesen. Zum Ursprung des Begriffs „Referendum“ und zu den verschiedenen Ausprägungen siehe ebd., S. 24.

4 Theo Schiller/Volker Mittendorf, Neue Entwicklungen der direkten Demokratie, in: dies. (Hrsg.), Direkte Demokratie - Forschung und Perspektiven, 2002, S. 13. 
Die erstgenannte Variante der direkten Demokratie als Herrschafts- bzw. Staatsform ist als solche in der Praxis nicht anzutreffen; in reiner Form war und ist sie nicht umsetzbar. ${ }^{5}$ Zwar wird in diesem Zusammenhang vielfach auf die Ausgestaltung des politischen Systems in der Schweiz bzw. in einigen Schweizer Kantonen verwiesen. Bei genauerer Betrachtung stellt sich indes auch das schweizerische System als ,halbdirekte Demokratie ${ }^{\text {“6 }}$ dar, bei welcher die durchaus stark ausgeprägten Volksrechte - zu denken ist vor allem an das sog. obligatorische Verfassungsreferendum ${ }^{7}$ - die repräsentativen Elemente lediglich ergänzen. Dies zeigt sich am deutlichsten an dem im schweizerischen Gesetzgebungsverfahren vorgesehenen sog. fakultativen (Gesetzes-)Referendum. Nach ihm sind nicht nur Gesetze, sondern auch völkerrechtliche Verträge, die unbefristet und unkündbar sind, oder die den Beitritt zu einer internationalen Organisation vorsehen oder eine multilaterale Rechtsvereinheitlichung herbeiführen, seitens des Parlaments mit einer Vorbehalts- oder Referendumsklausel zu versehen. Werden anschließend innerhalb von drei Monaten 50.000 Unterschriften gesammelt, wird der jeweilige Parlamentsbeschluss einer Volksabstimmung unterstellt. Das Gesetz tritt nur dann in Kraft, wenn die Mehrheit der Abstimmenden die Vorlage annimmt (sog. einfaches „Volksmehr"). ${ }^{8}$ Von den über 2.000 Gesetzen, welche das schweizerische Parlament seit 1874 verabschiedet hat, sind mehr als $90 \%$ ohne ein solches Referendum in Kraft getreten. ${ }^{9}$ Ähnliches gilt für die sog. Volksinitiative auf Totalrevision oder Teilrevision der Verfassung ${ }^{10}$ als weitere direkt-demokratische Besonderheit der Schweiz. Gemäß Art. 139 der schweizerischen Bundesverfassung vom 18. April 1999 (BV) ${ }^{11}$ haben 100.000 stimmberechtige Bürger die Möglichkeit, mit einer Volksinitiative beim Bund eine Ände-

5 Theo Schiller, Direkte Demokratie - eine Einführung, 2002, S. 16 f. Vgl. außerdem Schiller/Mittendorf, Entwicklungen (Fn. 4), S. 13, die zwischen einem „starken Ergänzungsstatus“ (wie bspw. in der Schweiz) und einem in der politischen Realität häufiger anzutreffenden „schwachen Ergänzungsstatus“ innerhalb eines ansonsten repräsentativ ausgestalteten Systems differenzieren.

6 Wolf Linder, Das politische System der Schweiz, in: Wolfgang Ismayr (Hrsg.), Die politischen Systeme Westeuropas, 4. Aufl. 2009, S. 567 (576). Zur „halbdirekten Demokratie“ siehe auch Philippe Mastronardi, Verfassungslehre, 2007, S. 258.

7 Diesem zufolge muss jede Verfassungsänderung in der Schweiz sowohl dem Volk als auch den 26 Kantonen zur Abstimmung vorgelegt werden und dabei das „doppelte Mehr“ erreichen (also der Abstimmenden selbst und der Kantone); vgl. Wolf Linder, Gesellschaftliche Spaltung und direkte Demokratie am Beispiel der Schweiz, in: Klemens H. Schrenk/Markus Soldner (Hrsg.), Analyse demokratischer Regierungssysteme, 2010, S. 599 (600).

$8 \quad$ Dazu Linder, System (Fn. 6), S. 577.

$9 \quad$ Linder, Spaltung (Fn. 7), S. 600.

10 Vgl. Art. 138 (Totalrevision) und Art. 139 (Teilrevision) der schweizerischen Bundesverfassung.

11 Der Text ist abrufbar unter: <http://www.admin.ch/ch/d/sr/101/index.html $>$. 
rung, Aufhebung oder Neuschaffung eines Verfassungsartikels zu verlangen. Kommt eine solche Volksinitiative innerhalb von 18 Monaten zustande, so wird sie vom Bundesrat und vom Parlament beraten und den Stimmbürgern anschließend mit einer Empfehlung vorgelegt. Sie gilt dann als angenommen, wenn sie in der anschließenden Abstimmung sowohl beim Volk als auch bei den Kantonen - analog zum obligatorischen Verfassungsreferendum - das „doppelte Mehr“ erreicht. ${ }^{12}$ Seit Einführung dieses direkt-demokratischen Rechts im Jahr 1891 hatten das schweizerische Volk und die Kantone über 175 solcher durch eine Volksinitiative vorgeschlagenen Verfassungsänderungen $\mathrm{zu}$ entscheiden; lediglich 18 waren erfolgreich. ${ }^{13}$ Selbst das direkt-demokratische „Paradebeispiel“" Schweiz zeigt somit, dass direkte Demokratie als staatsleitendes Prinzip keine bedeutende Rolle spielt und der politischen Realität allein nicht gerecht werden kann. ${ }^{14}$

Umso mehr überrascht es, welch weitreichende Konsequenzen Entscheidungen nach sich ziehen können, die im Wege direkter Demokratie seitens der Bevölkerung (mit-)entschieden wurden. Wird nämlich von jener ursprünglich bloß abstrakten Mitbestimmungsmöglichkeit zu bestimmten Sachfragen konkret Gebrauch gemacht - im Wege einer Volksinitiative, eines Referendums o.ä. -, können sich hieraus Auswirkungen auf die Ebene des internationalen Rechts, u.U. gar Konflikte mit dieser Ebene, ergeben. Diese Auswirkungen sind - jedenfalls außerhalb der Schweiz - bislang nur sporadisch analysiert worden; sie bilden den Gegenstand vorliegender Skizze. Im Vordergrund steht dabei die Frage, ob die Staaten aus der Perspektive des Völkerrechts solche direkt-demokratischen Entscheidungsinstrumentarien in ihren jeweiligen politischen Systemen überhaupt vorsehen dürfen, und in welchen Fällen die Inanspruchnahme direkt-demokratischer Entscheidungsmechanismen Berührungen oder gar Konflikte mit dem Völkerrecht - mit welchen Folgen - nach sich zieht. Zur Veranschaulichung werden zunächst konkrete Beispiele dargestellt, in denen sich die Ausübung direkter Demokratie auf der Ebene des internationalen Rechts ausgewirkt hat. Sie handeln zunächst von als problematisch erachteten Volksinitiativen jüngerer Zeit in der Schweiz und alsdann von Referenden, die international relevante Souverä-

12 Johannes Reich, Direkte Demokratie und völkerrechtliche Verpflichtungen im Konflikt, ZaöRV 68 (2008), S. 979 (983 f.).

13 Daten: <http://www.admin.ch/ch/d//pore/vi/vis_2_2_5_9.html >. Zu den 18 angenommen Initiativen gehören neben dem Beitritt der Schweiz zu den Vereinten Nationen (UN) auch die umstrittenen Vorlagen „Gegen den Bau von Minaretten“ (2009) oder „Ausschaffungsinitiative“"(2010). Auf sie wird noch näher eingegangen.

14 Vgl. auch Klaus Stern, Staatsrecht, Bd. I, 2. Aufl. 1984, S. 593: direkte Demokratie könne als „Erscheinungsform neuzeitlicher politischer Herrschaft nicht bestehen“; Lindner, System (Fn. 6), S. 576 spricht insoweit von der „Utopie direkter Demokratie“. 
nitäts- bzw. Territorialitätsfragen zum Inhalt hatten (sog. Unabhängigkeits- und Territorialplebiszite).

\section{Beispiele direkt-demokratischer Entscheidungsverfahren mit völkerrechtli- chen Bezügen}

\section{Volksinitiativen in der Schweiz}

Vor allem mehrere in der Schweiz durchgeführte Volksabstimmungen entfachten kontroverse Diskussionen hinsichtlich ihrer Vereinbarkeit mit Normen des geltenden Völkerrechts. ${ }^{15}$ So wurde in der Abstimmung vom 29. November 2009 die Volksinitiative „Gegen den Bau von Minaretten“ angenommen. Art. 72 Abs. 3 BV lautet nunmehr: „Der Bau von Minaretten ist verboten.“ Es entspricht nahezu einhelliger Auffassung (und wurde etwa auch vom schweizerischen Bundesrat geltend gemacht), ${ }^{16}$ dass diese neue Verfassungsbestimmung in Widerspruch zu internationalen Menschenrechtsgarantien, insbesondere zu Art. 9 (Gedanken-, Gewissens- und Religionsfreiheit) und Art. 14 (Verbot der Benachteiligung) der Europäischen Menschenrechtskonvention (EMRK), ${ }^{17}$ steht. $^{18}$

Die Minarettverbotsinitiative stellt keinen Einzelfall dar. Am 28. November 2010 wurde die ebenfalls hochumstrittene „Ausschaffungsinitiative“"19 angenommen, infolge deren der insoweit geänderte Art. $121 \mathrm{BV}$ in seinen neuen Absätzen 3 bis 6 nunmehr vorschreibt, dass in der Schweiz ansässige Ausländer, „unabhängig von ihrem ausländerrechtlichen Status, ihr Aufenthaltsrecht sowie alle Rechtsansprüche auf Aufenthalt in der Schweiz [verlieren]", wenn sie rechtskräftig für eines der in der Norm aufgezählten Delikte (u.a. vorsätzliche Tötung, Drogenhandel, Sexualdelikte) verurteilt wurden. Unabhängig von den im Hinblick auf die Verhältnismäßigkeit der Norm bestehenden Bedenken - so stellt ihrem Wortlaut zufolge bereits ein „Einbruchsdelikt“ oder der „,missbräuchliche Bezug von Leistungen der Sozialversicherungen oder der Sozialhilfe“ ein relevantes Delikt dar und führt unmittelbar zur Abschiebung - kann Art. 121

15 Vgl. die Nachweise bei Giovanni Biaggini, Die schweizerische direkte Demokratie und das Völkerrecht - Gedanken aus Anlass der Volksabstimmung über die Volksinitiative „Gegen den Bau von Minaretten“, ZÖR 65 (2010), S. 325 (332).

16 Vgl. Botschaft des Bundesrates an die Bundesversammlung zur Volksinitiative „Gegen den Bau von Minaretten“v v. 27. August 2008 (BB1. 2008, 7603 [7611 ff.]).

17 Europäische Konvention zum Schutz der Menschenrechte und Grundfreiheiten v. 4. November 1950 (BGB1. 1952 II S. 685).

18 Siehe nur Ralph Zimmermann, Zur Minarettverbotsinitiative in der Schweiz, ZaöRV 69 (2009), S. 829 (835 ff.); Biaggini, Demokratie (Fn. 15), S. 333, 336 ff.

19 Vgl. die polemische Webpräsenz der Initiative unter <http://www.ausschaffungsinitiative.ch $/>$. 
Abs. 3-6 BV mit verschiedenen internationalen Gewährleistungen in Konflikt treten. Neben dem im Genfer Abkommen über die Rechtsstellung der Flüchtlinge (Genfer Flüchtlingskonvention - GFK) ${ }^{20}$ normierten Non Refoulement-Prinzip (vgl. Art. 33 GFK) $)^{21}$ ist insoweit etwa an die Bestimmungen des seit dem 1. Juni 2002 in Kraft befindlichen Freizügigkeitsabkommens zwischen der Schweiz und der EU zu denken. ${ }^{22}$ Ferner erscheint auch hier - spätestens bei der konkreten Umsetzung dieser neuen Verfassungsnorm - ein Konflikt mit Rechten aus der EMRK, insbesondere mit dem Recht auf Familienleben (vgl. Art. 8 EMRK), geradewegs programmiert.

Schließlich sei in vorliegendem Zusammenhang noch auf die „Verwahrungsinitiative" vom 8. Februar 2004 hingewiesen. Aufgrund ihrer Annahme schreibt der geänderte Art. 123a Abs. 2 BV nunmehr vor, dass ein als ,extrem gefährlich [...] und nicht therapierbar“ eingestufter „Sexual- oder Gewalttäter [...] bis an sein Lebensende zu verwahren“" sei. Die Überprüfung dieser Maßnahme sei nur dann zulässig, ,wenn durch neue, wissenschaftliche Erkenntnisse erwiesen wird, dass der Täter geheilt werden kann und somit keine Gefahr mehr für die Öffentlichkeit darstellt." Es besteht kein Zweifel daran, dass auch Art. 123a Abs. 2 BV in seiner Undifferenziertheit zentralen menschenrechtlichen Garantien, insbesondere Art. 5 Abs. 4 EMRK und dem ähnlich gelagerten Art. 9 des Internationalen Pakts über bürgerliche und politische Rechte (IPBürg), ${ }^{23}$ widerspricht. ${ }^{24}$

\section{Unabhängigkeits- und Territorialplebiszite}

Im Unterschied zu dem soeben dargestellten direkt-demokratischen Instrument der Volksinitiative, das vor allem dadurch gekennzeichnet ist, dass die Bürger

20 Genfer Abkommen über die Rechtsstellung der Flüchtlinge v. 28. Juli 1951 (BGB1. 1953 II S. 559).

21 Dazu Walter Kälin/Martina Caroni/Lukas Heim, in: Andreas Zimmermann (Hrsg.), The 1951 Convention Relating to the Status of Refugees and its 1967 Protocol, 2011, Art. 33 $\S 1$.

22 Abkommen zwischen der Europäischen Gemeinschaft und ihren Mitgliedstaaten einerseits und der Schweizerischen Eidgenossenschaft andererseits über die Freizügigkeit v. 21. Juni 1999 (AB1. EG 2002, Nr. L 114/6).

23 Internationaler Pakt über bürgerliche und politische Rechte v. 19. Dezember 1966 (BGBl. 1973 II S. 1534).

24 Reich, Demokratie (Fn. 12), S. 1003 ff. - Nach Art. 5 Abs. 4 EMRK hat ,[j]ede Person, die festgenommen oder der die Freiheit entzogen ist, [...] das Recht zu beantragen, dass ein Gericht innerhalb kurzer Frist über die Rechtmäßigkeit der Freiheitsentziehung entscheidet und ihre Entlassung anordnet, wenn die Freiheitsentziehung nicht rechtmäßig ist." Zur fehlenden Vereinbarkeit der nachträglichen Sicherheitsverwahrung in Deutschland mit Art. 5 Abs. 1 EMRK vgl. EGMR, Application No. 19359/04, M. v. Deutschland, Urteil v. 17.12.2009, NJW 2010, 2495. 
gleichsam „von unten“25 ein konkretes Anliegen in den politischen Prozess einbringen und hierüber ein Abstimmungsverfahren durchführen, geht einem Referendum bzw. Plebiszit stets eine „fremde“ ${ }^{\text {26 }}$ Erarbeitung der Abstimmungsfrage voraus. ${ }^{27}$ Das Volk verfügt mithin nicht über inhaltliche Gestaltungsmöglichkeiten; vielmehr wird ihm - sozusagen ,von oben“ - eine bereits vorgefertigte Frage zur Entscheidung vorgelegt. ${ }^{28}$

Die nachfolgenden Beispiele konzentrieren sich auf solche Referenden, bei denen den Abstimmungsberechtigten - i.d.R. handelt es sich um ein „Volk ${ }^{629}$ konkrete Territorial- und/oder Souveränitätsfragen zur Entscheidung vorgelegt wurden. Im Vordergrund steht die Kategorie der sog. Unabhängigkeitsreferenden, in deren Rahmen die Bewohner eines abgegrenzten Territoriums alternativ über den weiteren Verbleib im bisherigen Staat (Autonomie) oder über die Ausrufung der eigenen staatlichen Unabhängigkeit abstimmen dürfen. Ein Blick auf die Vereinten Nationen (UN) offenbart die Bedeutung solcher Unabhängigkeitsreferenden für die Entstehung neuer Staaten: Gemessen am Beitrittsdatum sind die jüngsten Mitgliedsstaaten allesamt auf der Grundlage von Referenden entstanden (Südsudan 2011, Montenegro 2006, Osttimor 1999).

\section{a) Unabhängigkeitsreferendum im Südsudan}

Der Südsudan (offiziell „Republic of South Sudan“), eine ehemalige autonome Region des Sudans, erklärte sich am 9. Juli 2011 offiziell für unabhängig und ist seitdem nicht nur der jüngste Staat Afrikas und der gesamten Welt, sondern darüber hinaus - seit dem 14. Juli 2011 - auch das jüngste (193.) Mitglied der UN. Der Unabhängigkeitserklärung war die Durchführung eines Unabhängigkeitsreferendums vorausgegangen, welches vom 9. bis 15. Januar 2011 abgehalten worden war und in dessen Rahmen sich laut dem offiziellen amtlichen Ergebnis nahezu 99\% der Abstimmungsberechtigten für die Unabhängigkeit ausgesprochen hatten. Das Referendum ging wiederum auf ein Friedensabkommen von 2005 zurück (sog. Comprehensive Peace Agreement), ${ }^{30}$ welches den langjähri-

25 Schiller, Demokratie (Fn. 5), S. 14.

26 Tobias Franke-Polz, Direkte Demokratie, 2003, S. 10.

27 Stephan Büsching, Angst vor dem Volk! Die Diskussion um die Einführung plebiszitärer Elemente in das Grundgesetz, 2004, S. 21.

28 Aufgrund der möglichen strategischen Manipulierbarkeit stellt Schiller, Demokratie (Fn. 5), S. 14 die Zugehörigkeit des Referendums zum Bereich der direkten Demokratie insgesamt in Frage.

29 Zum völkerrechtlichen Volksbegriff siehe nur die Darstellung bei Stephan Hobe, Einführung in das Völkerrecht, 9. Aufl. 2008, S. 170 f.

30 Abrufbar unter: <http://unmis.unmissions.org/Portals/UNMIS/Documents/General/cpaen.pdf>. 
gen Bürgerkrieg um die Unabhängigkeit des Südsudans beendet hatte, und mit welchem dem Südsudan, nach einer sechsjährigen Phase der Autonomie, das Recht zur Durchführung eines solchen (Unabhängigkeits-)Referendums eingeräumt wurde.

\section{b) Unabhängigkeitsreferenden auf dem Gebiet des ehemaligen Jugoslawien}

Auf dem Gebiet der ehemaligen Sozialistischen Föderativen Republik Jugoslawien fanden mit Beginn der 1990er Jahre nicht nur eine Serie von Parlamentsund Präsidentschaftswahlen, sondern vor allem auch eine Reihe von Unabhängigkeitsreferenden statt. So war Slowenien am 8. April 1990 Schauplatz demokratischer Parlamentswahlen, die kurze Zeit später, am 23. Dezember 1990, von einem Unabhängigkeitsreferendum gefolgt wurden. In dessen Rahmen sprachen sich $88,2 \%$ der stimmberechtigten Bürger für die staatliche Unabhängigkeit aus. ${ }^{31}$ In Kroatien war der Ablauf nahezu identisch: Im Anschluss an die ersten Parlamentswahlen fand am 19. Mai 1991 auch hier ein Unabhängigkeitsreferendum statt, in dessen Rahmen fast 94\% der Abstimmenden für die staatliche Souveränität Kroatiens votierten. ${ }^{32} \mathrm{Zu}$ berücksichtigen ist allerdings, dass das Referendum vom Großteil der Bevölkerung in den serbischen Ballungsgebieten Kroatiens, insbesondere in der sog. Krajina, boykottiert wurde. ${ }^{33}$ Drei Jahre später kam es am 19./20 Juni 1993 in der inzwischen ausgerufenen „Serbischen Republik Krajina“ zur Abhaltung eines zweiten Referendums, in dessen Rahmen sich knapp 99\% der Abstimmenden für die staatliche Souveränität der „Republik Krajina“ und ihre Vereinigung mit der „Republika Srpska“ (in Bosnien) und anderen serbisch besiedelten Gebieten aussprachen.

Auch in Mazedonien folgte auf die Abhaltung der ersten Parlamentswahlen (11./25. November 1990) die Durchführung eines Unabhängigkeitsreferendums (7. September 1991), bei welchem 74,1\% der Abstimmenden die mazedonische Unabhängigkeit befürworteten. Ferner fanden am 18. November 1990 die ersten

31 Vgl. Peter Vodopivec, Slowenien, in: Dunja Melčić (Hrsg.), Der Jugoslawienkrieg Handbuch zur Vorgeschichte, Verlauf und Konsequenzen, 2. Aufl. 2007, S. 41.

32 Vgl. Holm Sundhaussen, Der Gegensatz zwischen historischen Rechten und Selbstbestimmungsrechten als Ursache von Konflikten: Kosovo und Krajina im Vergleich, in: ders./Philipp Ther (Hrsg.), Nationalitätenkonflikte im 20. Jahrhundert, 2001, S. 19.

33 Im Jahre 1991 stellten die Serben mit 12,2\% der Gesamtbevölkerung Kroatiens die größte ethnische Minderheit des Landes; vgl. Nenad Zakosek/Tomislav Marsic, Das politische System Kroatiens, in: Wolfgang Ismayr (Hrsg.), Die politischen Systeme Osteuropas, 3. Aufl. 2010, S. 773 (775). Die serbische Bevölkerung der Krajina hatte im Übrigen selbst einige Monate zuvor (am 19. August 1990) ein erstes Referendum abgehalten - unter Ausschluss der dort lebenden Kroaten -, in dessen Rahmen sich 90\% der Teilnehmer für einen Autonomiestatus aussprachen; vgl. Sundhaussen, Gegensatz (Fn. 32), S. 19. 
Parlamentswahlen in Bosnien-Herzegowina statt, die von einem Unabhängigkeitsreferendum - freilich erst am 29. Februar (bzw. 1. März) 1992 - gefolgt wurden. Wie im Falle Kroatiens boykottierte die serbische Bevölkerung in Bosnien-Herzegowina das Referendum, mit der Folge, dass sich lediglich 63\% der Stimmberechtigten daran beteiligten, von denen wiederum 99,4\% für die Unabhängigkeit Bosniens votierten. ${ }^{34}$ Auch in Bosnien-Herzegowina ging dem Boykott zunächst ein eigenes Referendum der bosnischen Serben voraus, in dessen Rahmen sich 90\% der Abstimmenden für den Verbleib Bosnien-Herzegowinas in der Jugoslawischen Republik aussprachen. Schließlich fand am 16./17. Mai 1993 auf dem Territorium der heutigen bosnischen Entität „Republika Srpska“ ein serbisch-dominiertes Referendum statt, in dessen Rahmen 96\% der Bevölkerung für die Unabhängigkeit jener „Republika Srpska“ und gleichzeitig für die Assoziationsfreiheit mit anderen Staaten stimmten. ${ }^{35}$

Auch auf dem Gebiet des Kosovo (am 30. September 1991) und in Montenegro (am 29. Februar bzw. 1. März 1992) wurden im fraglichen Zeitraum Unabhängigkeitsreferenden durchgeführt. In beiden Fällen hatte allerdings das Ergebnis des Referendums zunächst keine unmittelbaren Folgen für den Status der betroffenen Gebiete: Das Kosovo erklärte sich erst sechzehn Jahre später offiziell für unabhängig, wobei sein völkerrechtlicher Status auch drei Jahre nach der Unabhängigkeitserklärung umstritten ist,$^{36}$ während Montenegro seine staatliche Souveränität erst nach Durchführung eines weiteren Referendums im Mai 2006 erlangte, in dessen Rahmen sich 55,5\% der Abstimmenden für eine Auflösung der Föderation mit Serbien aussprachen. ${ }^{37}$ In den übrigen Fällen ist es demgegenüber nicht bei der Durchführung von Unabhängigkeitsreferenden geblieben. Vielmehr folgte auf den positiven Ausgang des Referendums jeweils unmittelbar die Erklärung der Unabhängigkeit. So erklärten sich sowohl Kroatien als auch Slowenien am 25. Juni 1991 offiziell für unabhängig; im Falle Mazedoniens geschah dies am 17. September 1991, im Falle Bosnien-Herzegowinas zeitgleich mit der Bekanntgabe des Ergebnisses des Referendums am 29. Februar bzw. 1. März 1992.

34 Sundhaussen, Gegensatz (Fn. 32), S. 19.

35 Vgl. Holm Sundhaussen, Geschichte Serbiens: 19.-21. Jhd., 2007, S. 414.

36 Hieran hat auch das im Auftrag der UN-Generalversammlung erstellte Gutachten des Internationalen Gerichtshofs (IGH) v. 22. Juli 2010 (abrufbar unter: <http://www.icjcij.org/docket/files/141/15987.pdf>) nichts geändert.

37 Vgl. zum Ganzen Florian Bieber, Das politische System Montenegros, in: Ismayr, Systeme Osteuropas (Fn. 33), S. 942 ff. Im Rahmen des ersten Referendums am 29. Februar /1. März 1992 hatten sich - bei einer Wahlbeteiligung von 66\% - noch 95\% der stimmberechtigten Bürger für einen Verbleib Montenegros im damaligen Jugoslawien entschieden. 
Die Dismembration ${ }^{38}$ der ehemaligen Sozialistischen Föderativen Republik Jugoslawien und der damit in unmittelbarem Zusammenhang stehende Ausbruch der Balkankriege zu Beginn der 1990er Jahre gehen maßgeblich auf die ersten beiden Unabhängigkeitserklärungen der früheren Teilrepubliken Slowenien und Kroatien zurück. Sowohl in Slowenien („Zehn-Tage-Krieg“) als auch in Kroatien folgten den Unabhängigkeitserklärungen heftige militärische Auseinandersetzungen mit dem damaligen Restjugoslawien. ${ }^{39}$ Das gleiche Schicksal ereilte 1992 bekanntlich auch Bosnien-Herzegowina; der anschließende dreijährige Bosnienkrieg konnte erst Ende 1995 durch das seitens der internationalen Gemeinschaft initiierte sog. Daytoner Friedensabkommen ${ }^{40}$ beendet werden, in dessen Rahmen zugleich eine gänzlich neue Verfassung für Bosnien-Herzegowina geschaffen und jenem Friedensvertrag (als Annex IV) beigefügt wurde. Aufgrund der ebenfalls im Friedensvertrag beschlossenen Errichtung des sog. Office of the High Representative ${ }^{41}$ stellt das Land bis heute eine Art „Quasi-Protektorat" der internationalen Gemeinschaft dar. ${ }^{42}$

Ob der Untergang Jugoslawiens tatsächlich als Dismembration zu qualifizieren war, oder ob nicht vielmehr - jedenfalls im Falle von Kroatien und Slowenien - der Tatbestand einer Sezession vorlag, wird bis heute kontrovers diskutiert. Die teilweise als voreilig bewertete Anerkennung Sloweniens und Kroatiens als eigenständige Staaten - insbesondere durch Deutschland - stellte die Völkerrechtsgemeinschaft vor gewisse Probleme: Da der geschilderte Ablauf der Ereignisse im ehemaligen Jugoslawien eher auf einen noch nicht abgeschlossenen Sezessionsprozess hindeutete, bedurfte es zur Vermeidung des Vorwurfs eines Verstoßes gegen das völkerrechtliche Interventionsverbot (infolge der vorzeitigen Anerkennung der nach Unabhängigkeit strebenden Gebilde) eines völkerrechtlichen Rechtfertigungsgrundes. Ein solcher konnte allenfalls in der Vorenthaltung des Selbstbestimmungsrechts der nach souveräner Unabhängigkeit strebenden Völker gesehen werden; so zu Recht Bernhard Kempen/Christian Hillgruber, Völkerrecht, 2007, § 4 Rn. 45 und $\S 20$ Rn. 56 m.w.N. Dessen ungeachtet wurden die Geschehnisse im 1. Gutachten der Schiedskommission der Jugoslawien-Konferenz (sog. Badinter-Kommission) v. 29.11. 1991 über den völkerrechtlichen Status der Sozialistischen Föderativen Republik Jugoslawien (abgedruckt in: EJIL 3 [1992], S. 182 f.) nicht als „Abspaltung(en)“, sondern als „Zerfall des ehemaligen Jugoslawiens“, d.h. als Dismembration (,dissolution“), bewertet. Zum Ganzen vgl. Christian Hillgruber, Die Aufnahme neuer Staaten in die Völkerrechtsgemeinschaft, 1998, S. 636 ff., 739 ff.; Volker Epping, in: Knut Ipsen, Völkerrecht, 5. Aufl. 2004, § 5 Rn. 18 m.w.N.

39 Zum Ganzen Erich Rathfelder, Der Krieg an seinen Schauplätzen, in: Melčić, Jugoslawienkrieg (Fn. 31), S. 344 ff.

40 General Framework Agreement for Peace in Bosnia and Herzegovina v. 14. Dezember 1995 (ILM 35 [1996], 75).

41 Dem Hohen Repräsentanten (zur Zeit der österreichische Diplomat Valentin Inzko) stehen weitreichende innerstaatliche Befugnisse zu (sog. Bonn Powers), welche ihn u.a. dazu ermächtigen, ,to remove from office public officials who violate legal commitments and the Dayton Peace Agreement, and to impose laws as he sees fit if Bosnia and Herzegovina's legislative bodies fail to do so" (<http://www.ohr.int/>).

42 Siehe Wolfgang Graf Vitzthum/Marcus Mack, Multiethnischer Föderalismus in BosnienHerzegowina, in: Wolfgang Graf Vitzthum (Hrsg.), Europäischer Föderalismus. Suprana- 
Abschließend sei auf ein letztes - vergleichsweise aktuelles - Referendum mit völkerrechtlichen Implikationen hingewiesen. Seit nahezu zwei Jahrzehnten besteht zwischen Slowenien und Kroatien ein Streit um die Abgrenzung ihrer Territorien in der Bucht von Piran. Jedenfalls mittelbar ist dieser Streit auf die bereits erwähnten Unabhängigkeitserklärungen beider Staaten vom 25. Juni 1991 zurückzuführen. Damals hatte die Badinter-Kommission in ihrem zweiten Gutachten vom 2. November $1991^{43}$ im Hinblick auf die zukünftige Grenzziehung festgelegt, dass im Sinne des völkerrechtlichen uti possidetis-Prinzips ${ }^{44}$ die bisherigen internen Grenzen der ehemaligen jugoslawischen Teilrepubliken die Staatsgrenzen der nunmehr unabhängigen souveränen Staaten darstellen sollten. ${ }^{45}$ Das Problem lag im vorliegenden Fall allerdings darin, dass die Seegrenzen bis dahin nie festgelegt worden waren. ${ }^{46}$

Kroatien interpretierte jenen Beschluss der Badinter-Kommission im Sinne von Art. 15 des UN-Seerechtsübereinkommens (SRÜ), ${ }^{47}$ wonach im Falle einander gegenüberliegender oder aneinander angrenzender Küsten kein Staat berechtigt sei, „sein Küstenmeer über die Mittellinie auszudehnen, auf der jeder Punkt

tionaler, subnationaler und multiethnischer Föderalismus in Europa, 2000, S. 81 (116): „subsidiäres de-facto Protektorat“; vgl. auch Solveig Richter/Saša Gavrić, Das politische System Bosnien und Hercegovinas, in: Ismayr, Systeme Osteuropas (Fn. 33), S. 837 (844).

43 Abgedruckt in: EJIL 3 (1992), S. 183 ff.

44 Beim uti possidetis-Prinzip handelt es sich um eine besondere Ausprägung des völkerrechtlichen Effektivitätsgrundsatzes, demzufolge ein bestimmtes Gebiet einem Staat dann zugerechnet wird, wenn er darüber während eines längeren Zeitraums tatsächliche und unbestrittene Herrschaftsgewalt ausgeübt hat. In diesem Sinne bedeutet der Begriff ,uti possidetis“ zunächst die völkerrechtliche Anerkennung der faktischen Innehabung zum Zeitpunkt einer Streitbeilegung oder eines Friedensschlusses. Heute wird das Prinzip überwiegend als eine Art Besitzstandgarantie im Sinne einer Garantie der territorialen Integrität der Staaten und somit als Verpflichtung zur Respektierung bestehender Grenzen verstanden, vgl. Epping, Völkerrecht (Fn. 38), § 23 Rn. 7 f. Vgl. auch IGH, Frontier Dispute (Burkina Faso v. Mali), Urteil v. 22.12.1986, ICJ Reports 1986, 554 (566 f.).

45 Jochen A. Frowein, Self-Determination as a Limit to Obligations under International Law, in: Christian Tomuschat (Hrsg.), Modern Law of Self-Determination, 1993, S. 211 (216 f.) bezweifelt, ob die Badinter-Kommission das uti possidetis-Prinzip im Falle des ehemaligen Jugoslawiens zutreffend angewendet habe, und zeigt sich ,surprised about the boldness with which very difficult issues of public international law are being decided in a clear-cut manner without much argument."

46 Vgl. nur Johanna Deimel, Die zwischenstaatlichen, regionalen und ethnischen Spannungen im Donauraum: Ungeklärte Territorial- bzw. Grenzfragen, in: Eckart D. Stratenschulte/Florian H. Setzen (Hrsg.) Der europäische Fluss: Die Donau und ihre Regionen als Strategieraum, 2011, S. 138.

47 Seerechtsübereinkommen der Vereinten Nationen v. 10. Dezember 1982 (BGBl. 1994 II S. 1799). 
gleich weit von den nächstgelegenen Punkten der Basislinien entfernt ist, von denen aus die Breite des Küstenmeers jedes der beiden Staaten gemessen wird.“ Slowenien hielt dem entgegen, dass die Bucht von Piran bis zum Tag der Unabhängigkeitserklärungen beider Staaten faktisch unter alleiniger slowenischer Verwaltung gestanden habe, und berief sich damit unmittelbar auf das uti possidetis-Prinzip. Hauptziel Sloweniens war dabei die Absicherung eines freien $\mathrm{Zu}$ gangs zu internationalen Gewässern, was im Rahmen der von Kroatien auf der Grundlage von Art. 15 SRÜ favorisierten Mittellinienlösung nicht gewährleistet gewesen wäre. ${ }^{48}$

Letztlich verlagerte sich der Grenzstreit auf die EU-Ebene. Slowenien, seit 2004 ein EU-Mitgliedsstaat, machte von seinem Veto-Recht Gebrauch, um den Annäherungsprozess EU - Kroatien zu behindern. ${ }^{49}$ Begründet wurde diese Vorgehensweise damit, dass Kroatien im Rahmen seiner EU-Beitrittsverhandlungen angeblich Dokumente und Landkarten beigefügt habe, die den Grenzstreit präjudizieren würden. Das slowenische EU-Veto sorgte nicht nur für spürbare Verstimmungen im bilateralen Verhältnis zu Kroatien, sondern auch für Unverständnis auf Seiten der europäischen Institutionen. ${ }^{50}$ Nicht zuletzt aufgrund des größer werdenden Drucks seitens der EU kam es schließlich am 4. November 2009 in Stockholm zur Unterzeichnung eines Abkommens beider Länder, ${ }^{51}$ in welchem die verbindliche Lösung des Grenzstreits einem teilweise international besetzten Schiedsgericht anvertraut wurde. Allerdings vereinbarten die Vertragsparteien gleichzeitig, dass das entsprechende Abkommen von den Parlamenten beider Länder ratifiziert werden müsse. Dies führte in Slowenien dazu, dass jener völkerrechtliche Vertrag einem Volksentscheid unterworfen wurde. ${ }^{52}$ Am 6. Juni

48 Eingehend Michael Allmendinger, Buchten im Völkerrecht, 2006, S. 228 ff.

49 Bereits 2004 hatte der Rat dem Beginn von Beitrittsverhandlungen dem Grunde nach zugestimmt, ihn aber zahlreichen Bedingungen unterworfen; vgl. Beschluss des Rates v. 13. September 2004 über die Grundsätze, Prioritäten und Bedingungen der Europäischen Partnerschaft mit Kroatien (AB1. EG 2004, Nr. L 297/19).

50 Vgl. nur folgende Presseberichte: „Nach EU-Veto gegen Kroatien: Druck auf Slowenien steigt“, abrufbar unter: <http://diepresse.com/home/politik/eu/439136/Nach-EUVeto-gegen-Kroatien_Druck-auf-Slowenien-steigt>; ,Veto gefährdet EU-Fahrplan Kroatiens“, abrufbar unter: <http://derstandard.at/1227289106937>. Vgl. außerdem Deimel, Spannungen (Fn. 46), S. $138 \mathrm{f}$.

51 Arbitration Agreement between the Government of the Republic of Slovenia and the Government of the Republic of Croatia, abrufbar unter: <http://www.vlada.si/filead$\mathrm{min} /$ dokumenti/si/projekti/2010/Arbitrazni_sporazum/10.a_Arbitra\%C5\%BEni_sporazu m_-_podpisan_EN.pdf $>$.

52 Gemäß Art. $9 \overline{0}$ der slowenischen Verfassung (abrufbar unter: <http://www.pf.uni-mb.si/ datoteke/holcman/esn-cttn-ale.pdf $>$ ) kann das slowenische Parlament ,über Fragen, die durch Gesetz geregelt werden, ein Referendum ausschreiben." Gemäß Satz 2 ist das Parlament hierzu verpflichtet, wenn mindestens ein Drittel der Abgeordneten des insgesamt 90-köpfigen Parlaments dies verlangt. Ein solches Vorgehen hatten die slowenischen Oppositionsparteien unmittelbar nach der Unterzeichnung des Schiedsgerichtsabkom- 
2010 stimmten die slowenischen Bürger darüber ab, ob das unterzeichnete Schiedsgerichtsabkommen auch in Slowenien in Kraft treten könne (das kroatische Parlament hatte der Übereinkunft bereits im November 2009 zugestimmt). Das Referendum fiel denkbar knapp aus: lediglich 51,46 \% der Abstimmenden sprachen sich für die Annahme des Abkommens aus. ${ }^{53}$ Die Wahlbeteiligung lag bei $42,3 \% .{ }^{54}$ Das Schiedsverfahren soll dem Abkommen zufolge an dem Tag beginnen, an dem Kroatien den EU-Beitrittsvertrag unterschreibt.

\section{Direkte Demokratie im Kontext der europäischen Integration}

Jedenfalls in einem weiteren Sinne wirken auch die im Kontext der europäischen Integration durchgeführten direkt-demokratischen Entscheidungsverfahren auf die internationale Ebene ein. So sorgten die in einzelnen Mitgliedsstaaten durchgeführten Referenden zum Vertrag von Lissabon - vor allem in Frankreich, den Niederlanden und Irland - für großes Aufsehen. In Irland wurde die Ratifizierung des Vertrags bekanntlich von der Mehrheit der Abstimmenden, d.h. auf direkt-demokratischem Wege, abgelehnt. Dass ein einzelner Staat unter Bezugnahme auf die nach nationalem Recht erforderliche Durchführung eines Volksentscheids die Fortentwicklung eines internationalen Vertrags für alle übrigen Vertragsparteien gänzlich stoppen kann, ist im Falle der EU indes nicht Ausdruck eines Konflikts zwischen innerstaatlich vorgesehenen direkt-demokratischen Elementen einerseits und dem internationalen Recht andererseits. Das Vetorecht ist im EU-Vertrag ${ }^{55}$ vielmehr selbst ausdrücklich vorgesehen - gemäß Art. 48 Abs. 4 EUV müssen Änderungen ,von allen Mitgliedstaaten nach Maßgabe ihrer verfassungsrechtlichen Vorschriften ratifiziert“" werden ${ }^{56}$-, und sämtliche Mitgliedsstaaten haben sich dieser Regelung mit ihrem Beitritt freiwillig unterworfen. Die Referenden werden vorliegend daher nicht näher untersucht.

Hinzuweisen ist schließlich auf die mit dem Vertrag von Lissabon auf der EUEbene eingeführte Europäische Bürgerinitiative, das erste originär europäische,

mens angekündigt, vgl. den „Länderbericht“ der Konrad-Adenauer Stiftung: Reinhard Wessel, Kroatien und Slowenien unterzeichnen Schiedsgerichtsabkommen zur Lösung des Grenzstreits, abrufbar unter: <http://www.kas.de/wf/doc/kas_18028-1522-130.pdf?091108143831>.

53 Vgl. den zweiten „Länderbericht“ der Konrad-Adenauer Stiftung: Reinhard Wessel, Slowenen stimmen Schiedsgerichts-Abkommen zum Grenzstreit zwischen HR und SLO mit knapper Mehrheit zu, abrufbar unter: <http://www.kas.de/wf/doc/kas_19849-1522-130.pdf?100909121750>.

54 Ein Beteiligungsquorum ist seitens der slowenischen Verfassung nicht vorgegeben.

55 Vertrag über die Europäische Union v. 7. Februar 1992 in der Fassung des Vertrags von Lissabon v. 13. Dezember 2007 (konsolidierte Fassung: AB1. EU 2010, Nr. C 83/13).

Für das vereinfachte Änderungsverfahren vgl. Art. 48 Abs. 6 EUV. 
und somit zwischenstaatliche, Instrument direkter Demokratie, das ab dem 1. April 2012 allen EU-Bürgern zur Verfügung stehen soll. ${ }^{57}$ Freilich handelt sich um ein bloßes Initiativrecht der Unionsbürger, demgegenüber eine verbindliche Abstimmung nicht vorgesehen ist. Eine durchgeführte Initiative bindet selbst die EU-Kommission, auf deren Befugnisse sie ausgerichtet ist, nicht.

\section{Völkerrechtliche Bewertung}

Im Folgenden sollen zunächst die geschilderten Unabhängigkeitsreferenden (Südsudan und ehemaliges Jugoslawien) völkerrechtlich bewertet werden, bevor den schweizerischen Volksinitiativen und dem slowenischen Referendum Aufmerksamkeit geschenkt wird.

\section{Völkerrechtliche Bewertung der Unabhängigkeitsreferenden}

Die völkerrechtliche Einordnung derjenigen Unabhängigkeitsreferenden, die in der Folge jeweils in die staatliche Souveränität des nach Unabhängigkeit strebenden Gebildes mündeten, hat bei folgender Feststellung anzusetzen: Auch in Fällen mit Zustimmungsergebnissen von weit über $90 \%$ zog die Abhaltung der Referenden keineswegs automatisch die staatliche Unabhängigkeit nach sich. Völkerrechtlich konnten sich die Referenden von vornherein nicht unmittelbar auf die Ebene des für alle Staaten verbindlichen Völkerrechts auswirken und also unmittelbar zur Entstehung eines neuen Staates führen. Hierfür lassen sich ein materiell-rechtlicher und ein formeller Begründungsansatz anführen.

In formeller Hinsicht belegen die dargestellten Beispiele zunächst, dass sich die alleinige Durchführung eines Unabhängigkeitsreferendums nicht unmittelbar auf die Ebene des internationalen Rechts auswirken kann, weil hierfür nach der Staatenpraxis ein zusätzliches Erfordernis erfüllt sein muss: die Unabhängigkeitserklärung. Erst sie macht den mittels eines Referendums gewonnenen Volkswillen nach außen hin sichtbar. Besonders deutlich wird dieses Erfordernis am Beispiel des Südsudan. Obwohl dem Südsudan das Recht zur Durchführung eines Unabhängigkeitsreferendums im Rahmen des CPA völkervertraglich eingeräumt worden war und obschon das Referendum eine 99\%ige Zustimmung der Bevölkerung für die Unabhängigkeit zum Ausdruck gebracht hatte, änderte die

57 Vgl. Art. 11 Abs. 4 EUV und Art. 24 des Vertrags über die Arbeitsweise der Europäischen Union (AEUV) in der Fassung des Vertrags von Lissabon v. 13. Dezember 2007 (konsolidierte Fassung: ABl. EU 2008, Nr. C 115/47) und dazu nur Bruno Kaufmann, Direkte Demokratie auf transnationaler Ebene, JdD 2 (2010), S. $201 \mathrm{ff}$. 
alleinige Durchführung des Referendums im Januar 2011 am zunächst weiterhin bestehenden Autonomiestatus Südsudans unmittelbar nichts. Eine Statusveränderung im Rechtssinne trat erst sechs Monate später mit der offiziellen Erklärung der Unabhängigkeit ein. Sie bildete die Grundlage dafür, dass der Südsudan als souveräner Staat in den Genuss der damit verbundenen Rechte gelangte und etwa die Mitgliedschaft in den UN beantragten konnte. Die Anerkennungspraxis gegenüber dem Südsudan bestätigt das gefundene Ergebnis. Unabhängig von der seit Dekaden umstrittenen Frage, ob der völkerrechtlichen Anerkennung eines Staates deklaratorische oder konstitutive Wirkung zukommt, ${ }^{58}$ sind sich die Vertreter beider Ansichten darin einig, dass eine vorzeitige Anerkennung gegen das völkerrechtliche Interventionsverbot verstößt. ${ }^{59} \mathrm{Um}$ der Gefahr einer solchen Rechtsverletzung aus dem Wege zu gehen, hatte kein Staat - trotz der an sich klaren objektiven Lage - den Südsudan vor dem 9. Juli 2011, d.h. vor der offiziellen Erklärung der südsudanesischen Unabhängigkeit, anerkannt. Auch die teilweise zuvor beschlossenen ${ }^{60}$ Anerkennungen - so auch seitens der Bundesrepublik Deutschland - wurden ausnahmslos mit dem Zusatz „mit Wirkung zum 9. Juli 2011" versehen. ${ }^{61}$

In materiell-rechtlicher Hinsicht differenziert das Völkerrecht in gewisser Weise zwischen legitimen und illegitimen Referenden. Diese Differenzierung stützt sich nicht etwa auf die Frage, ob dem jeweils nach Unabhängigkeit strebenden Gebilde innerstaatlich bzw. staatsrechtlich das Recht zur Durchführung eines solchen Volksentscheids zusteht. Diese ist auf der Grundlage des nationalen Rechts zu beantworten. Ebenso wenig wie das Völkerrecht in der Lage ist, einzelnen Staaten die konkrete Ausgestaltung ihrer jeweiligen innerstaatlichen Ordnung vorzuschreiben, ${ }^{62}$ ist einzelnen Staaten die Nichteinhaltung völkerrechtlicher Verpflichtungen mit dem Hinweis auf die abweichende Ausgestaltung der innerstaatlichen Ordnung gestattet. ${ }^{63}$ Vorliegend geht es vielmehr ausschließlich

58 Ausführlich dazu etwa Malcom N. Shaw, International Law, 6. Aufl. 2008, S. 445 ff.; James Crawford, The Creation of States in International Law, 2. Aufl. 2006, S. $17 \mathrm{ff}$.

59 Vgl. nur Shaw, International Law (Fn. 58), S. 460 ff.

60 Der Beschluss einer zukünftigen Anerkennung ist nicht mit der tatsächlichen Erklärung der Anerkennung gleichzusetzen; erst Letztere führt im bilateralen Verhältnis zu einer Veränderung der völkerrechtlichen Lage.

61 Vgl. die tabellarische Auflistung der einzelnen Erklärungen aller Staaten, die den Südsudan bisher anerkannt haben (samt Datum und etwaigen Zusätzen), unter: $<$ http://de.wikipedia.org/wiki/Internationale_Anerkennung_des_S\%C3\%BCdsudan>.

62 Auf diesen Aspekt wird im weiteren Verlauf, insbesondere im Rahmen der Auswertung der schweizerischen Volksinitiativen bzw. des slowenischen Volksentscheids zum Grenzabkommen, noch näher eingegangen.

63 Zum Vertragsrecht vgl. Art. 27 des Wiener Übereinkommens über das Recht der Verträge (WVK) v. 23. Mai 1969 (BGBl. 1985 II S. 927). Jener Grundsatz ist sowohl für das dualistische als auch das monistische Verständnis des Verhältnisses von Völkerrecht und 
um die Frage nach der völkerrechtlichen Legitimität eines Referendums, die nicht anhand der innerstaatlichen Ausgestaltung bewertet werden kann. ${ }^{64}$ Diesbezüglich lässt sich immerhin eindeutig beantworten, wem im Rahmen des Völkerrechts ein Recht zur Durchführung eines Referendums zugewiesen ist. Als Konkretisierung des Selbstbestimmungsrechts der Völker, wie es in Art. 1 Nr. 2 UN-Charta als Zielvorgabe und in Art. 1 Abs. 1 der beiden Menschenrechtspakte von $1966^{65}$ als Recht ausgestaltet wurde, steht die Organkompetenz jedenfalls einem „Volk“ im völkerrechtlichen Sinne zu. ${ }^{66}$ An dieser völkerrechtlichen $\mathrm{Zu}$ weisung kann die verfassungsrechtliche Ausgestaltung innerhalb eines Staates nichts ändern. Wiederum nicht entscheidend für die völkerrechtliche Legitimität eines Referendums ist demgegenüber, ob sich - rein quantitativ - ein repräsentativer Anteil der Stimmberechtigten, d.h. der Angehörigen des betreffenden Volkes, am Entscheid beteiligt hat. Die Höhe der Beteiligung vermag lediglich den innerstaatlichen Grad der demokratischen bzw. politischen Legitimität des Ergebnisses eines Referendums zu beeinflussen.

Die völkerrechtliche Bewertung der Legitimität eines Referendums und der sich daraus ergebenden Konsequenzen sei vorliegend am Beispiel der Mitte 1993 in den sog. Serbenrepubliken durchgeführten Unabhängigkeitsreferenden veranschaulicht. Wie gezeigt sprach sich sowohl in der "Serbischen Republik Krajina“ in Kroatien als auch in der „Republika Srpska“ (RS) in Bosnien im Rahmen von Referenden die in den beiden Gebieten lebende serbische Bevölkerung jeweils mit großer Mehrheit für die staatliche Unabhängigkeit der beiden Gebiete aus. Zwar stand Letzteren gemäß der damaligen jugoslawischen Verfassung von 1974 gar nicht das Recht zur Durchführung solcher Referenden - oder gar das Recht anschließender Sezessionen $-\mathrm{zu} ;{ }^{67}$ wie festgestellt, spielt die auf die nationale

innerstaatlichem Recht anerkannt; vgl. Philip Kunig, Völkerrecht und staatliches Recht, in: Wolfgang Graf Vitzthum (Hrsg.), Völkerrecht, 5. Aufl. 2010, 2. Abschnitt, Rn. 33.

In vorliegendem Kontext steht die Kategorie der Legitimität, nicht aber die der Legalität zur Diskussion, weil ein Volksentscheid - anders als eine Sezession - unmittelbar keine völkerrechtlichen Folgen hervorruft und also selbst nicht am positiven Recht gemessen werden kann. Selbst in dem Fall, dass Gegenstand eines Referendums eine Frage ist, die zu einem Verstoß gegen Menschenrechte führen kann, ist nicht die Durchführung des Referendums selbst, sondern erst seine ggf. anschließend erfolgende Umsetzung am Völkerrecht zu messen.

65 IPBürg (Fn. 23); Internationaler Pakt über wirtschaftliche, soziale und kulturelle Rechte v. 19. Dezember 1966 (IPWirt - BGB1. 1973 II S. 1570).

66 Dazu siehe Fn. 29.

67 Anders hingegen im Hinblick auf die sechs Teilrepubliken des ehemaligen Jugoslawiens: Die Reform der jugoslawischen Verfassung von 1974 hatte zu einem intensiven Ausbau des Föderalismus und damit zu einer starken Dezentralisierung des (Gesamt-)Staates geführt. In diesem Rahmen wurde den sechs Teilrepubliken verfassungsrechtlich ein Recht auf Sezession zugesprochen. Dementsprechend war die Durchführung der Unabhängigkeitsreferenden und die anschließende Erklärung der staatlichen Unabhängigkeit im Falle 
Ebene beschränkte Verfassungswidrigkeit der Referenden für ihre völkerrechtliche Bewertung aber keine Rolle. Des Weiteren verfügten beide Gebilde zum Zeitpunkt der Referenden bereits über stabile Staatsstrukturen. So existierten beispielsweise in der RS bereits ein gewähltes Präsidium (Radovan Karadžić) und ein Parlament, welches durchaus effektive Staatsgewalt über ein (ethnisch definiertes, nämlich serbisches) Volk auf einem abgegrenzten Gebiet ausübte. Für sich betrachtet lagen somit die gewohnheitsrechtlich anerkannten Voraussetzungen für die Staatlichkeit (Staatsgebiet, Staatsvolk, Staatsgewalt ${ }^{68}$ vor, die es mit der anschließenden Durchführung der Referenden lediglich noch zu bestätigen galt. Deshalb stellt sich die Frage, welche Relevanz dem - letztlich im Selbstbestimmungsrecht der Völker fußenden - Gesichtspunkt der völkerrechtlichen Legitimität der unmittelbar auf einem positiven Volksentscheid beruhenden Unabhängigkeitserklärung überhaupt zukommen kann.

Bei der Beantwortung dieser Frage hilft ein Blick in die Friendly Relations Declaration der UN-Generalversammlung. ${ }^{69}$ Dort heißt es zunächst:

„Die Gründung eines souveränen und unabhängigen Staates, die freie Assoziation mit einem unabhängigen Staat, die freie Eingliederung in einen solchen Staat oder der Eintritt in einen anderen, durch ein Volk frei bestimmten politischen Status sind Möglichkeiten der Verwirklichung des Selbstbestimmungsrechts durch das betreffende Volk."

$\mathrm{Zu}$ einem etwaigen, aus dem Selbstbestimmungsrecht der Völker abgeleiteten Recht auf Sezession wird allerdings konkretisiert:

„Die vorstehenden Absätze sind nicht so auszulegen, als ermächtigten oder ermunterten sie zu Maßnahmen, welche die territoriale Unversehrtheit oder die politische Einheit souveräner und unabhängiger Staaten [ganz oder teilweise auflösen oder beeinträchtigen würden], die sich gemäß dem [...] Grundsatz der Gleichberechtigung und Selbstbestimmung der Völker verhalten und die daher eine Regierung besitzen, welche die gesamte Bevölkerung des Gebiets ohne Unterschied der Rasse, des Glaubens oder der Hautfarbe vertritt.“

Hiernach manifestiert sich das Selbstbestimmungsrecht der Völker grundsätzlich nicht in einem Recht auf Sezession, wenn in einem Staat das Selbstbestimmungsrecht der Völker beachtet und das Verlangen eines Volkes nach Selbstregierung oder Autonomie nicht gewaltsam unterdrückt wird. Wenn überhaupt, kann ein Recht auf Sezession im Zusammenhang mit dem Selbstbestimmungs-

Kroatiens, Sloweniens, Mazedoniens und Bosnien-Herzegowinas Anfang der 1990er Jahre verfassungsrechtlich ebenso legal wie legitim.

68 Sog. Drei-Elemente-Lehre, vgl. Georg Jellinek, Allgemeine Staatslehre, 3. Aufl. 1914, S. 394 ff. Vgl. auch Art. 1 der Montevideo Convention on the Rights and Duties of States v. 26. Dezember 1933 (165 L.N.T.S. 19): „The state as a person of international law should possess the following qualifications: (a) a permanent population; (b) a defined territory; (c) government; and (d) capacity to enter into relations with the other states."

69 UN Doc. A/RES/2625 (XXV) v. 24. Oktober 1970, Declaration on Principles of International Law concerning Friendly Relations and Co-operation among States in accordance with the Charter of the United Nations. 
recht der Völker nur als Konsequenz dauerhafter Verweigerung der Selbstbestimmung und gravierender Menschenrechtsverletzungen entstehen. ${ }^{70}$

Die Geltendmachung eines unabhängigen Staates „Republika Srpska“ durch das (ethnische) Volk der bosnischen Serben und damit die Geltendmachung eines Rechts auf Sezession unter Berufung auf das Selbstbestimmungsrecht der Völker ist unter den vorgenannten Bedingungen ausgeschlossen. Entscheidend ist insoweit nicht nur die Tatsache, dass im Falle der „Republika Srpska“ alle konstitutiven Staatsmerkmale (Staatsgebiet, Staatsvolk, Staatsgewalt) zum Zeitpunkt der Durchführung des Referendums bereits vorlagen, sondern auch und gerade, wie es - insbesondere in so kurzer Zeit - zur Schaffung und Erfüllung der konstitutiven Staatselemente und zu dem überdeutlichen Ergebnis des anschließenden Unabhängigkeitsreferendums gekommen ist. Was das Gebilde „Republika Srpska“" anbelangt, waren massive Vertreibungen und sog. ethnische Säuberungen der nicht-serbischen Bevölkerung - mithin gravierende Menschenrechtsverletzungen und also Verstöße gegen Normen mit erga omnes-Charakter ${ }^{71}$ - erforderlich, um innerhalb kürzester Zeit ein zusammenhängendes Gebiet, und somit ein „Staatsgebiet“, sowie auf diesem Gebiet eine serbische Bevölkerungsmehrheit, und damit ein „Staatsvolk“, buchstäblich zu kreieren. In großen Teilen der heutigen „Republika Srpska“, insbesondere im Osten und Norden des Gebiets, waren vor dem Krieg keine serbischen (Volks-)Mehrheiten vorhanden, im Gegenteil: Dort stellten vor dem Bosnienkrieg die Bosniaken die größte Volksgruppe dar. Mit Ausbruch des Krieges fand eine Verschiebung insoweit statt, als nunmehr die Serben im gesamten Gebiet der „Republika Srpska“ die größte

70 Die Frage nach dem Bestand eines Sezessionsrechts in krassen Ausnahmesituationen ist bis heute heftig umstritten. Der IGH hat diese Frage, ,a subject on which radically different views were expressed by those taking part in the proceedings and expressing a position on the question“ $(\S 82)$, in seinem Gutachten zur einseitigen Unabhängigkeitserklärung des Kosovo offen gelassen; vgl. Accordance with International Law of the Unilateral Declaration of Independence in Respect of Kosovo, Gutachten v. 22. Juli 2010, abrufbar unter: <http://www.icj-cij.org/docket/files/141/15987.pdf>, § 83. Im Ergebnis verneinend etwa Shaw, International Law (Fn. 58), S. 291 m.w.N.

71 Vgl. IGH, Barcelona Traction, Light and Power Co. Ltd. (Belgium v. Spain) (Second Phase), Urteil v. 5. Februar 1970, ICJ Reports 1970, 3 (32); vgl. auch die Resolution 941 des UN-Sicherheitsrats v. 23. September 1994, mit welcher der Sicherheitsrat die ethnischen Säuberungen auf dem Gebiet des ehemaligen Jugoslawiens als Verletzungen des humanitären Völkerrechts verurteilte. Die UN-Generalversammlung hatte in ihrer Resolution v. 18. Dezember 1992 (UN Doc. A/Res. 47/121) die ethnischen Säuberungen auf dem Gebiet des heutigen Bosnien-Herzegowina sogar als Akt des Völkermords qualifiziert. Ähnlich äußerte sich auch das Kriegsverbrechertribunal für das ehemalige Jugoslawien (International Criminal Tribunal for the Former Yugoslavia - ICTY): ,there are obvious similarities between a genocidal policy and the policy commonly known as ,ethnic cleansing““ (Krstić, IT-98-33-T, Trial Chamber Judgment v. 2.8.2001, para. 562). 
Volksgruppe bildeten. ${ }^{72}$ Die Geltendmachung eines Sezessionsrechts unter Berufung auf das Selbstbestimmungsrecht der Völker erscheint unter solchen Umständen unzulässig. Hieran, und damit auch an dem fortwährenden Status quo der Nicht-Staatlichkeit, vermag in Falle der „Republika Srpska“ (und der „Serbischen Republik Krajina") auch der mittels des Referendums deutlich zum Ausdruck gebrachte Unabhängigkeitswille des Volkes der bosnischen Serben nichts zu ändern. Die auf Ebene der Legalität angesiedelte, i.d.R zu verneinende Frage nach dem Bestand eines Sezessionsrechts und die nach der Legitimität eines Unabhängigkeitsreferendums hängen demnach unmittelbar miteinander zusammen.

Das Beispiel verdeutlicht Folgendes: Zum einen ändert die Abhaltung des Referendums zunächst - und zwar unabhängig vom erzielten Ergebnis - nichts am völkerrechtlichen Status des jeweiligen Gebildes. Zum anderen behält sich die internationale Gemeinschaft, auch bei solch eindeutigen Ergebnissen wie im Falle der „Republika Srpska“, eine - jedenfalls konkludent erfolgende - „letztinstanzliche Bewertung“ der völkerrechtlichen Legitimität eines Referendums bzw. des Unabhängigkeitsstrebens einer Entität vor. In diesem Sinne ist zwar zunächst zu berücksichtigen, dass die Durchführung eines Unabhängigkeitsreferendums völkerrechtlich als Ausfluss des Selbstbestimmungsrechts der Völker zu qualifizieren ist. Seitdem das Selbstbestimmungsrecht in seiner Wirkung nicht mehr auf den Dekolonisierungsprozess beschränkt ist, ${ }^{73}$ besteht, wie gesagt, weitestgehend Einigkeit darüber, dass ein Sezessionsrecht unter Berufung auf das Selbstbestimmungsrecht der Völker allenfalls in ganz bestimmten Ausnahmefällen zuzulassen ist. Nichtsdestotrotz muss als Kehrseite der universellen Ausdehnung des Selbstbestimmungsrechts die Möglichkeit bestehen, auf etwaigen Missbrauch jenes Rechtsinstituts adäquat zu reagieren. Dies wird durch einen Überprüfungsvorbehalt der Staatengemeinschaft gewährleistet, dessen Anwendung zugleich ausdrücklicher oder konkludenter Ausdruck der Legitimität oder Illegitimität eines Unabhängigkeitsreferendums ist.

Wie bereits dargestellt, erfüllt(e) die „Republika Srpska“" generell alle objektiven Kriterien der Eigenstaatlichkeit. Auch wurde der entsprechende Wille des Volkes mit dem Ergebnis des durchgeführten Referendums eindeutig zum Ausdruck gebracht. Demzufolge bliebe bei einer rein objektiv-faktischen Anwendung der Staatskriterien letztlich nur der Schritt der Akzeptanz der staatlichen Unabhängigkeit. Ohne „letztinstanzliche“ Bewertung, und mag diese auch nur konkludent erfolgen, missachtete dieses Ergebnis indes, dass sowohl die Erfüllung der konstitutiven Staatselemente als auch das eindeutige Ergebnis des an-

72 Alle Daten abrufbar unter: <http://www.auswaertiges-amt.de/DE/Aussenpolitik/Laender/Laenderinfos/BosnienUndHerzegowina/Innenpolitik_node.html>.

73 Vgl. nur Georg Dahm/Jost Delbrück/Rüdiger Wolfrum, Völkerrecht, Bd. I/2, 2. Aufl. 2002, S. $287 \mathrm{f}$. 
schließenden Referendums nur durch vorherige, zum Teil gravierende Verstöße gegen (zwingende) Normen des Völkerrechts ermöglicht wurden. Die Fähigkeit und der Wille eines jeden Staates zur Beachtung und Einhaltung bestehender völkerrechtlicher Verpflichtungen stellen als Bestandteile der effektiven Staatsgewalt maßgebliche Kriterien von Staatlichkeit im völkerrechtlichen Sinne dar. ${ }^{74}$ Wie aber soll ein neuer Staat Gewähr dafür bieten, dass er in der Zukunft dauerhaft und zuverlässig die Geltung des Völkerrechts in dem von ihm effektiv beherrschten Gebiet garantieren kann, wenn er bereits den anfänglichen Prozess der Staatswerdung nur mittels gravierender Völkerrechtsverstöße zu bewältigen vermag? Ein solches Gebilde hat gewissermaßen von Beginn an gezeigt, dass es prinzipiell nicht in der Lage ist bzw. nicht die Fähigkeit und/oder den Willen besitzt, zumindest die grundlegenden völkerrechtlichen Verpflichtungen zu erfüllen und einzuhalten. Hieran ändert auch die Durchführung eines im Ergebnis eindeutigen Referendums nichts. Ohne abschließende Bewertungsmöglichkeit stünde der internationalen Gemeinschaft keine Möglichkeit zur Verfügung, ihrem Selbstverständnis als Rechtsgemeinschaft entsprechend zu reagieren, indem sie einer derartigen Schaffung vollendeter Tatsachen - insbesondere dann, wenn sie im gravierenden Widerspruch zum geltenden Völkerrecht zustande gekommen sind - einen Riegel vorschiebt. Letztlich wird die Existenz einer solchen „letztinstanzlichen Prüfungskompetenz" auch von der anerkannten (wenn auch auf ausdrücklicher Aufforderung seitens der UN-Organe beruhenden) Praxis der kollektiven Nichtanerkennung bestätigt, ${ }^{75}$ mit welcher einem Gebilde trotz Erfüllung der Staatskriterien die Rechtsstellung als Staat vorenthalten wird. ${ }^{76}$

74 Siehe nur Kempen/Hillgruber, Völkerrecht (Fn. 38), § 4 Rn. 14.

75 Vgl. ebd., § 4 Rn. 16 ff.; für die konstitutive Anerkennungstheorie ähnlich Sir Hersch Lauterpacht, Recognition in International Law, 1948, S. 55. - Natürlich ist die soeben dargestellte „letztinstanzliche Bewertung“ der Legitimität eines Unabhängigkeitsreferendums nicht mit der völkerrechtlichen Anerkennung bzw. Nichtanerkennung gleichzusetzen. Vielmehr ist die Legitimitätsfrage gewissermaßen eine Vorstufe zur Anerkennung; mangelt es bereits an der Legitimität des Unabhängigkeitsreferendums, stellt sich letztlich gar nicht die Frage, ob das jeweilige Gebilde als Staat anerkannt werden soll oder nicht. Diese Differenzierung wird deutlich, wenn der völkerrechtliche Status der „Republika Srpska“" mit dem - weiterhin umstrittenen (siehe Fn. 70) - völkerrechtlichen Status des Kosovo verglichen wird: Während Letzterer von mehr als einem Drittel aller Staaten anerkannt wurde (und der IGH in seinem bereits erwähnten Gutachten zumindest bestätigt hat, dass die einseitige Unabhängigkeitserklärung des Kosovo nicht gegen Normen des Völkerrechts verstößt), wird eine Anerkennung der „Republika Srpska“ auch von solchen Staaten, die sich seit jeher dem serbischen Volk politisch verbundenen fühlen (bspw. die Russische Föderation oder die Volksrepublik China), gemieden.

76 Siehe Stefan Talmon, Kollektive Nichtanerkennung illegaler Staaten, 2006, S. 259 ff. 


\section{Völkerrechtliche Bewertung der sachbezogenen Referenden}

Nimmt man die schweizerischen Volksinitiativen einerseits und den slowenischen Volksentscheid zum Grenzabkommen mit Kroatien andererseits in den Blick, drängt sich zunächst folgende Fragestellung auf: Kann das Völkerrecht das Problem nicht gewissermaßen an seinem Ursprung angehen, indem es bereits die innerstaatliche abstrakte Zurverfügungstellung solcher direkt-demokratischer Entscheidungsinstrumente für alle Staaten gleichermaßen verbindlich ,untersagt"? Die Antwort auf diese Frage muss negativ ausfallen. Die Entscheidung für oder gegen die abstrakte Gewährung von direkt-demokratischen Mitentscheidungs- und Mitgestaltungsmöglichkeiten, mit Hilfe deren die Abstimmungsberechtigten auf konkrete politische Sachfragen unmittelbar einwirken und diese somit selbst (mit-)gestalten können, unterliegt grundsätzlich der Souveränität der Staaten. Letztere gewährleistet als „Dreh- und Angelpunkt des Völkerrechts“677 in Form des Interventionsverbots, dass andere Staaten sich grundsätzlich nicht in den Bereich der inneren Angelegenheiten (sog. domaine réservé) einmischen dürfen. ${ }^{78} \mathrm{Zu}$ den inneren Angelegenheiten wird dabei vor allem der Bereich gezählt, der bislang noch keinen völkerrechtlichen Regelungen unterworfen ist; die domaine réservé ist insofern einem steten Wandel unterworfen. $\mathrm{Zu}$ den bislang erfassten Angelegenheiten zählt vor allem das Recht eines Staates zur freien Wahl und Ausgestaltung seines innerstaatlichen politischen, sozialen, wirtschaftlichen und kulturellen Systems. ${ }^{79}$ Damit eng verbunden ist die innere Dimension des Selbstbestimmungsrechts der Völker, aufgrund deren ein Volk frei und ohne Einmischung von außen über seinen politischen Status entscheiden und daher seine wirtschaftliche, soziale und kulturelle Entwicklung frei gestalten kann. ${ }^{80}$

Freilich hat sich der Bereich der inneren Angelegenheiten in den letzten Jahrzehnten erheblich verkleinert. So ist zwar die Wahl des sozialen, wirtschaftlichen oder auch des kulturellen Systems im Grundsatz weiterhin jedem Staat bzw. Staatsvolk selbst überlassen; für die konkrete Ausgestaltung des politischen Systems gilt diese Freiheit allerdings nicht mehr schrankenlos. Vielmehr findet in diesem ehemals ausschließlich den Staaten vorbehaltenen Bereich eine zunehmende Verdichtung der völkerrechtlichen Pflichten der Staaten statt, die dazu führt, dass die Anforderungen des Völkerrechts an die innere Organisation und

78 Für die Vereinten Nationen ist das Interventionsverbot in Art. 2 Nr. 7 UN-Charta explizit geregelt. Für die einzelnen Staaten gilt das Verbot weiterhin völkergewohnheitsrechtlich, da es an einer vergleichbaren Vertragsnorm für das zwischenstaatliche Verhältnis fehlt. Vgl. nur Matthias Herdegen, Völkerrecht, 9. Aufl. 2010, § 33 Rn. 3.

80 Siehe Kay Hailbronner/Marcel Kau, Der Staat und der Einzelne als Völkerrechtsubjekte, in: Graf Vitzthum, Völkerrecht (Fn. 63), 3. Abschnitt, Rn. 123. 
verfassungsrechtliche Struktur der einzelnen Staaten stetig steigen. Dies sei anhand der beiden folgenden Beispiele skizziert:

Das für die Staatlichkeit konstitutive Element der Ausübung effektiver Hoheitsgewalt setzt voraus, dass das betreffende Gebilde über die Fähigkeit zur Aufrechterhaltung der Ordnung im Innern und zur Einhaltung bestehender völkerrechtlicher Verpflichtungen nach außen verfügt. ${ }^{81} \mathrm{Zu}$ den klassischen völkerrechtlichen Verpflichtungen jedes Staates gehört u.a. die Beachtung des völkergewohnheitsrechtlich geltenden Fremdenrechts. Diesem zufolge ist jeder (Aufenthalts-)Staat zu einer dem völkerrechtlichen Mindeststandard entsprechenden Behandlung fremder Staatsangehöriger auf seinem Staatsgebiet verpflichtet. ${ }^{82}$ Die Beachtung der Regeln des gewohnheitsrechtlichen Fremdenrechts kann allerdings nur ein solches Herrschaftsgebilde gewährleisten, das Inhaber des Gewaltmonopols auf einem Territorium ist. ${ }^{83}$ Von daher setzt bereits die Völkerrechtsebene eine solche innerstaatliche Ausgestaltung des politischen Systems voraus, die es ermöglicht, der im Verhältnis Heimatstaat/Aufenthaltsstaat zum Tragen kommenden grundlegenden zwischenstaatlichen Verpflichtung zur Beachtung des Fremdenrechts nachkommen zu können.

Kommt es im Rahmen des dargestellten Fremdenrechts noch primär auf den Schutz des Heimatstaates und dessen Souveränität (in Form der Personalhoheit) an - der Schutz des Individuums erfolgt hier im Sinne eines bloßen Reflexes -, hat sich seit Ende des Zweiten Weltkriegs ein System des Menschenrechtsschutzes entwickelt, das das Individuum zum unmittelbar Begünstigten zwischenstaatlich begründeter und durchsetzbarer Rechte macht. ${ }^{84}$ Auf die Einzelheiten des völkerrechtlich gebotenen Mindeststandards bei der Beachtung der Menschenrechte kann vorliegend nicht eingegangen werden. Freilich steht außer Frage, dass nur ein solcher Staat jenem Mindeststandard Rechnung tragen kann, der nicht nur das Gewaltmonopol auf seinem Territorium innehat, sondern dessen Verfassungsordnung der rule of law verpflichtet ist. ${ }^{85}$

Die Beispiele des gewohnheitsrechtlichen Fremdenrechts einerseits und der dynamischen Entwicklung des völkerrechtlichen Menschenrechtsschutzes andererseits verdeutlichen, dass sich das Völkerrecht durchaus unmittelbar auf die

81 Siehe nur Kempen/Hillgruber, Völkerrecht (Fn. 38), § 4 Rn.7 m.w.N.

82 Zum Ganzen Ipsen, in: ders., Völkerrecht (Fn. 38), § 50 Rn. 2 ff.

83 Vgl. Markus Heintzen, Das staatliche Gewaltmonopol als Strukturelement des Völkerrecht, Der Staat 25 (1986), S. 17 (30 ff.).

84 Nicht abschließend geklärt ist, ob die gewohnheitsrechtliche Pflicht zur Gewährleistung eines menschenrechtlichen Mindeststandards gegenüber allen auf dem Staatsgebiet anwesenden Personen (also auch den eigenen Staatsangehörigen) den jeweiligen Staat bloß im Verhältnis zu anderen Staaten trifft, oder ob diese Pflicht schon gegenüber dem Individuum selbst besteht. Letzteres noch verneinend Ipsen, Völkerrecht (Fn. 38), § 50 Rn. 11. Vgl. Kempen/Hillgruber, Völkerrecht (Fn. 38), § 4 Rn. 8. 
konkrete Ausgestaltung der inneren Ordnung eines Staates auswirken kann. Zugleich bestätigen die aufgezeigten Einschränkungen der domaine réservé des Staates die ursprüngliche These, wonach die abstrakte Gewährung direkt-demokratischer Entscheidungsinstrumente im Rahmen der Ausgestaltung der innerstaatlichen Ordnung mit dem Völkerrecht vereinbar ist. Wurde soeben festgestellt, dass der ursprünglich den Staaten ausschließlich vorbehaltene Bereich der Gestaltung der inneren Ordnung in jüngerer Zeit durch die Entwicklung des völkerrechtlichen Menschenrechtsschutzes eingeschränkt wurde, kann in einem „Erst-Recht-Schluss“ die Konsequenz gezogen werden, dass ein Staat, dessen innere Ordnung direkt-demokratische Entscheidungsverfahren vorsieht - der also seiner Bevölkerung weitreichende Mitwirkungs- und Mitgestaltungsmöglichkeiten an den politischen Entscheidungen eröffnet -, den Ansprüchen der Völkerrechtsebene an die konkrete Ausgestaltung der domaine réservé im Grundsatz in besonderer Weise gerecht wird. Inneres Selbstbestimmungsrecht und klassische Menschenrechte treten insofern in eine enge sachliche Beziehung, was mit der Aufnahme des Selbstbestimmungsrechts in Art. 1 der beiden Menschenrechtspakte von 1966 korrespondiert. Einer derartigen Ausgestaltung der innerstaatlichen politischen Ordnung liegt die grundlegende Maxime zugrunde, den Volkswillen in weitestgehender Form in den politischen Entscheidungsprozess einfließen zu lassen. Mithin steht das Völkerrecht dergleichen Beteiligungsformen nicht entgegen.

Etwas anderes kann jedoch im Hinblick auf das konkrete Ergebnis eines Volksentscheids gelten. Dieses muss mit den in casu anwendbaren völkerrechtlichen Vorgaben etwa zum Menschenrechtsschutz vereinbar sein, will der Staat, der sich das Ergebnis eines gesetzlich vorgesehenen Referendums zurechnen lassen muss, vermeiden, für eine Völkerrechtsverletzung verantwortlich gemacht zu werden. Zur Vermeidung solcher Konflikte sind die Staaten selbst in der Lage, indem sie beispielsweise solche Referenden von vornherein nicht zulassen, die gegen das Völkerrecht verstoßen. ${ }^{86}$ Aus innerstaatlicher Perspektive kommt es in diesem Zusammenhang maßgeblich darauf an, welcher Rang dem Völkerrecht in der nationalen Rechtsordnung zugewiesen ist. Für die völkerrechtliche Beurteilung ist hingegen irrelevant, ob die mit dem Ergebnis des Volksentscheids kollidierenden Normen zum Bereich des zwingenden Rechts (jus cogens) zählen oder nicht. ${ }^{87}$ In Deutschland hat das Bundesverfassungsgericht, um Wertungswidersprüche zu vermeiden, aus einer Gesamtschau der nach außen gerichteten Bestimmungen des Grundgesetzes deshalb das Gebot der völkerrechtsfreundlichen

86 Zu Möglichkeiten in der Schweiz vgl. Biaggini, Demokratie (Fn. 15), S. 339 ff.

87 Vgl. die entsprechende Einschränkung in Art. 139 Abs. 2 BV. 
Auslegung des deutschen Rechts abgeleitet. ${ }^{88}$ Dabei handelt es sich um eine Konfliktvermeidungsregel, die jedenfalls zur Anwendung gelangt, wenn und soweit eine innerstaatliche Rechtsnorm mehrere Deutungen zulässt. ${ }^{89}$ In einem solchen Fall ist derjenigen Interpretation der Verzug zu geben, die gleichzeitig den Anforderungen des Völkerrechts gerecht wird. Dies gelte selbst dann, wenn die innerstaatliche Rechtsnorm zeitlich später entstanden sei; denn es sei „nicht anzunehmen, dass der Gesetzgeber, sofern er dies nicht klar bekundet hat, von völkerrechtlichen Verpflichtungen der Bundesrepublik Deutschland abweichen oder die Verletzung solcher Verpflichtungen ermöglichen will.“ ${ }^{“ 90}$

\section{Ergebnis}

Im Ergebnis führt die Durchführung eines Referendums selbst nicht zu einer unmittelbaren Änderung der völkerrechtlichen Lage. Mit Blick auf Unabhängigkeits- und Territorialplebiszite ist für eine unmittelbare Veränderung der Völkerrechtslage die formelle Erklärung der Unabhängigkeit erforderlich, welcher nicht bloß deklaratorischer Charakter zukommt. Überdies behält sich die Staatengemeinschaft eine Überprüfung der Legitimität des durchgeführten Referendums vor, die in engem Zusammenhang mit dem rechtlichen Bestand des materiellrechtlichen Unabhängigkeitsanspruchs steht. Referenden zu Sachfragen finden zwar im inneren Selbstbestimmungsrecht der Völker eine Grundlage; paradoxerweise kann ihr Ausgang aber zur völkerrechtlichen Verantwortlichkeit eines Staates führen, wenn nicht auf nationaler Ebene Mechanismen implementiert wurden, die die Vermeidung von Wertungswidersprüchen zwischen den Anforderungen des Völkerrechts einerseits und der nationalrechtlichen Umsetzung durchgeführter Volksentscheide andererseits gewährleisten.

Vgl. nur BVerfGE 58, 1 (34); 59, 63 (89); 64, 1 (20); 74, 358 (370); aus der Literatur Christian Tomuschat, Die staatsrechtliche Entscheidung für die internationale Offenheit, in: Josef Isensee/Paul Kirchhof (Hrsg.), Handbuch des Staatsrechts der Bundesrepublik Deutschland, 1. Aufl., Bd. VII, 1992, § 172 Rn. 27.

89 Siehe Alexander Proel $\beta$, Der Grundsatz der völkerrechtsfreundlichen Auslegung im Lichte der Rechtsprechung des BVerfG, in: Hartmut Rensen/Stefan Brink (Hrsg.), Linien der Rechtsprechung des Bundesverfassungsgerichts, 2009, S. 553 (557 ff.). - In seiner Entscheidung zum Bau der Waldschlösschenbrücke in Dresden stellte das Bundesverfassungsgericht fest, dass völkervertragliche Verpflichtungen einer Entscheidung für die Umsetzung eines Bürgerentscheids ,,als authentische Ausdrucksform unmittelbarer Demokratie“ nicht „,notwendig“ entgegenstünden; vgl. BVerfG EuGRZ 2007, S. 355 (358). Es trug damit dem innerstaatlich begründeten Umstand Rechnung, dass das Demokratieprinzip als gegenüber den völkerrechtlichen Vorgaben der UNESCO-Welterbekonvention höherrangige Verfassungsnorm geeignet ist, den Grundsatz der völkerrechtsfreundlichen Auslegung zurückzudrängen. 
